\title{
Minimization of Soil Pollution in the Urban Environment
}

\author{
Yulia Mikhailovna Galitskova \\ Samara state technical University \\ Architecture and construction Academy \\ Samara, Russia \\ galickova@yandex.ru
}

\begin{abstract}
The development of all spheres of human activity is associated with an increase in anthropogenic pressure on environment. Metropolitan areas and large cities are experiencing the greatest pressure. Both the development of new areas adjacent to built-up areas, as well as operating existing industrial and residential complexes suffer the influences. The article presents the results of a soil study conducted in the city of Novokuibyshevsk to determine the prospects for future growth of the city. Soil samples were taken throughout the city. When choosing the place of sampling, the locations of highways, industrial zones and residential buildings were taken into account. Soil testing was carried out to obtain data on the concentrations of heavy metals (lead, zinc, copper, cadmium, nickel, manganese, etc.), as well as sulfates and nitrates. The results were analyzed and contrasted with the standards and results of previous years.
\end{abstract}

Based on the study of the current state of the soil, the authors assessed the degree of pollution of urban soils in an industrial city. In their study they proposed and developed measures to improve the condition of the soil, namely, analyzed the efficiency of using phytoremediation to reduce soil contamination in residential areas of the city.

Keywords-land reclamation, soil contamination, phytoremediation, soil examination, urban areas.

\section{INTRODUCTION}

Heavy metals today belong to the group of the most dangerous toxic pollutants. The ingress of metals into ecosystems leads to irreversible changes and disruption of vital functions in many living organisms.

The main advantages of urbanized areas lie in their suitability for ornamental plants, the ability to absorb pollutants in depth and keep them from penetrating into the soil and groundwater. When first heavy metals get

into the depth of soddy-podzolic soil, they gradually come into contact with a layer of litter [1] - [3].

These contacts manifest themselves in different ways. On the one hand, litter layer acts as a trap for heavy metals, and on the other hand, the acquired saturation with watersoluble organic elements leads to the transformation of metals into a more migratory-active form.

Moreover, the predominance of heavy metals within the ecosystem leads to their increased accumulation by plant organisms [4] - [5]. As a result, we face changes in the mass and composition of tree waste, in the nature of its decomposition, and in the transformation of the humus state of the soil. Changes in the properties of the soil cause changes in soil processes and states, secondary pollution of the urban area soil layer. The degree of soil contamination, in turn, affects the attractiveness of residential areas. It is no surprise that areas with a high level of pollution are less attractive for the working population [6] - [9].

The objective of this study is to assess the degree of urban soil pollution and to investigate the effectiveness of using phytoremediation to reduce soil contamination [10] - [12]. Phytoremediation is a highly efficient technology for the decontamination from a number of organic and inorganic pollutants. The potential of phytoremediation for treating the areas contaminated with toxic agents causes great interest in the sturdy of further restoration of the environment by plants. In recent years, this technology has gained great popularity, which is directly related to its low cost [13] - [18].

\section{Materials AND METHODS}

To determine the degree of soil contamination, samples were taken in each area of the industrial city (Fig. 1). Soil samples were also collected around the Petrochemical complex within a radius of 5-6 km.

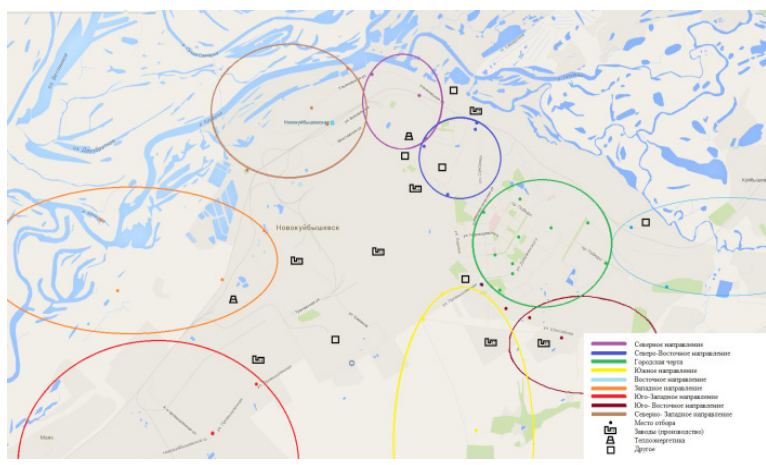

Fig. 1. Soil study areas.

Soil samples were collected according to the following wind rose directions: north, south, west, east, southwest and south-east, at a distance of 0 to $6 \mathrm{~km}$ from the source of pollution. A test site of $100 * 100 \mathrm{~m}$, completely reflecting the soil structure of the study area, was 
selected near the fixed points. Sampling was carried out according to the "envelope" method of the test site: four additional test pits were dug round each of the five points. A monolith measuring $10 * 10 * 20 \mathrm{~cm}$ was cut from a pit with a soil knife.

Of the twenty-five individual samples of approximately equal mass, a mixed sample was made up, from which remains of vegetation, stones, etc., had been removed. The soil was ground, mixed, then packed in a cloth bag or paper box to be delievered to the laboratory.

Analysis of the samples taken is carried out in the laboratory of the Center for Monitoring Environmental Pollution. The measurements were taken using calibrated instruments. Harmful substances were determined according to the approved methods. The soil samples were examined for heavy metals: cadmium, manganese, copper, nickel, lead, zinc, aluminium.

In case there were not any agreed upon MPC values for a specific element, the values obtained were compared with the APC values. The findings were then set against the background reference levels for pollutants in the soils of Samara region (i.e. regional concentration clarkes) to determine the degree of soil contamination in Novokuybyshevsk.

The next stage of research was to determine the effectiveness of phytoremediation in the urban environment. For this, petunia seeds were used.

Soil for conducting experiments on the composition and degree of contamination was taken similar to that obtained in the first part of the research. The focus was on pollutants such as zinc and copper.

\section{RESULTS AND DISCUSSION}

The results of soil contamination study are presented in Fig. 2. Following the retrieval, the Quantum-Z atomic absorption spectrometer was used to test the samples for the presence of the main pollutants: aluminum $(\mathrm{Al})$, cadmium $(\mathrm{Cd})$, manganese $(\mathrm{Mn})$, copper $(\mathrm{Cu})$, nickel $(\mathrm{Ni})$, lead $(\mathrm{Pb})$, zinc $(\mathrm{Zn})$. This method is based on the phenomenon of selective absorption of optical radiation (light) by free atoms of chemical elements.

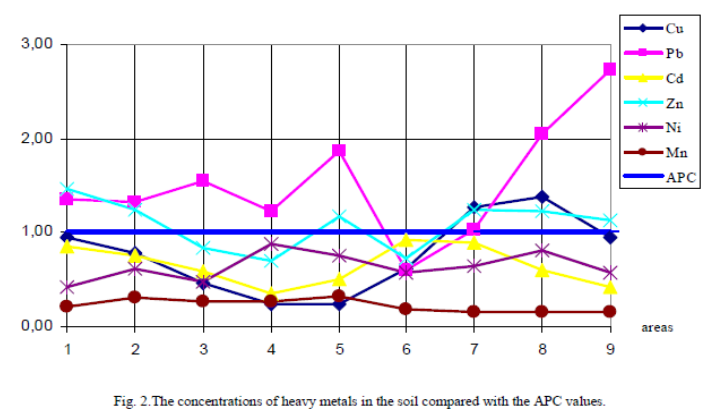

Fig. 2. The results of the analysis of soil contamination.

In the soils of the city, the average $\mathrm{Cu}$ content was $15.3 \mathrm{mg} / \mathrm{kg}$. The study proved that in two soil samples (areas No. 7, 8), the $\mathrm{Cu}$ content exceeded the regional background and ranged from 25.5 to $27.7 \mathrm{mg} / \mathrm{kg}$.
However, in two areas the values obtained exceeded those of the regional concentration clarke $(20 \mathrm{mg} / \mathrm{kg})$ by $27.5 \%$ (Group 7 - south-west) and by 39\% (group 8).

Analysis of the total $\mathrm{Pb}$ content in sample soils showed that its concentrations exceeded the background level across the board. The concentration of lead ranged from 6 to $27 \mathrm{mg} / \mathrm{kg}$, with the average at $15.26 \mathrm{mg} / \mathrm{kg}$, which did not exceed the MPC value $(32 \mathrm{mg} / \mathrm{kg})$, but was $53 \%$ higher than the background reference level $(10 \mathrm{mg} /$ $\mathrm{kg}$ ). The maximum value reached 1.8 MAC. The average lead content in the city was $0.5 \mathrm{MAC}$. The values of the regional concentration clarke were exceeded in seven areas out of nine.

The analysis of data on the content of $\mathrm{Cd}$ in soils showed that its content in samples taken from the northern, western and southwestern areas was much closer to the regional value The average and maximum content of cadmium in the soil of the city was observed at the level of 0.2-0.4 of a permissible value.

The content of $\mathrm{Zn}$ in all soil samples was lower than the existing MAC, although in some cases the number of total forms of $\mathrm{Zn}$ in the soil was at the level of its background. The following zinc concentration values were obtained: the maximum value at $73.5 \mathrm{mg} / \mathrm{kg}$, the minimum value at $36.3 \mathrm{mg} / \mathrm{kg}$ and the average value at $54 \mathrm{mg} / \mathrm{kg}$. As the MPC value for zinc is $220 \mathrm{mg} / \mathrm{kg}$, these values were within permissible limits. However, when set againstthe background reference levels $(50 \mathrm{mg} / \mathrm{kg})$, the values obtained exceeded the background values by 13 $47 \%$ in six areas.

The maximum nickel concentration at $35.35 \mathrm{mg} / \mathrm{kg}$ did not exceed neither the MPC value $(80 \mathrm{mg} / \mathrm{kg})$, nor the regional concentration clarke $(40 \mathrm{mg} / \mathrm{kg})$ in any of the areas. Similar results were obtained for nickel and manganese.

The average aluminum content in the soil of the city was observed at the level of $6224 \mathrm{mg} / \mathrm{kg}$ (5.4 of background values), the maximum $-7936 \mathrm{mg} / \mathrm{kg}$ (6.9 of background).

For planting, averaged concentrations of pollutants were taken (Table 1). Petunia seeds were planted in two containers.

Table I. Contaminants In Soil Before Planting

\begin{tabular}{|c|c|c|}
\hline \multirow{2}{*}{$\begin{array}{c}\text { Container } \\
\text { No. }\end{array}$} & \multicolumn{2}{|c|}{ Heavy metals in container soil, mg/kg } \\
\cline { 2 - 3 } & Zinc & Copper \\
\hline 1 & 46.5 & 15.3 \\
\hline 2 & 532.8 & 343.5 \\
\hline
\end{tabular}

Intensive care (watering, extra light) provided the first shoots after 15 days. Figure 3 shows that the plant in tank No. 1 (controlled) noticeably predominates in development than the plant in tank No. 2. 


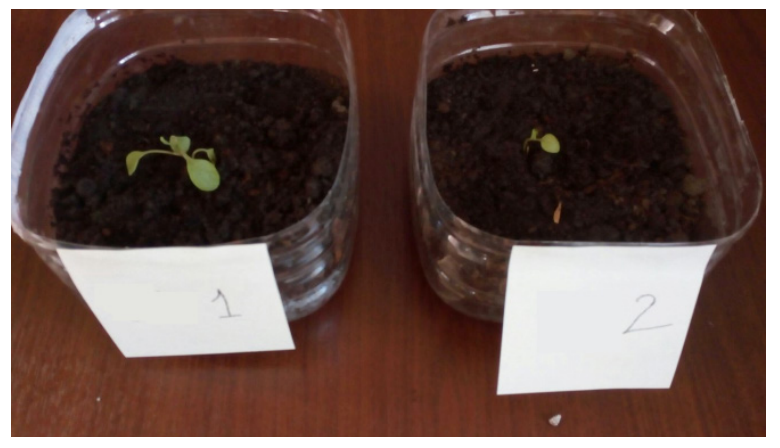

Fig. 3. The first shoots of petunias.

The stem of both plants is dense. The leaves are green, with no visible changes (Fig.4). Petunia in container No. 2 develops more slowly, without visible negative changes. Figure 5 shows that the petunia planted in container No. 2 is still lagging behind in development.

Despite the soil contaminated with heavy metals $(\mathrm{Zn}$ and $\mathrm{Cu}$ ), petunia seedlings showed satisfactory development. At the same time there was a significant decrease in the concentration of pollutants in the soil. For example, the concentration of copper decreased by 3 times, and the concentration of zinc by 1.5 times. From this we can conclude that the plant absorbs zinc in smaller quantities.

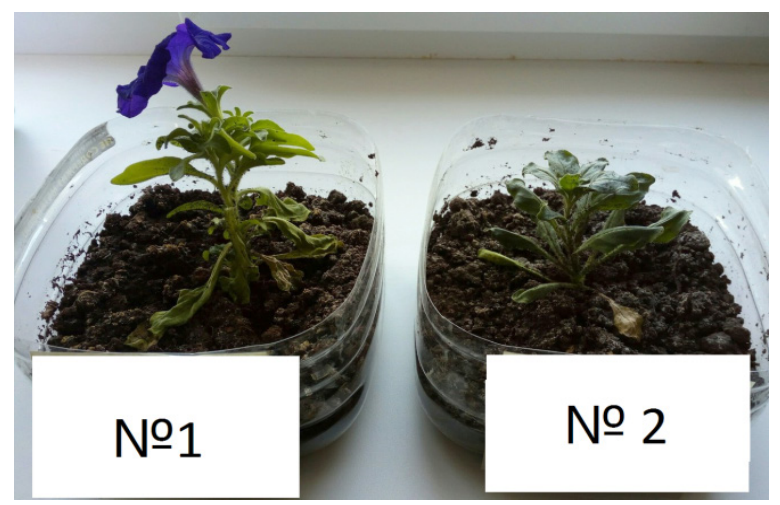

Fig. 4. Plants after 38 days.

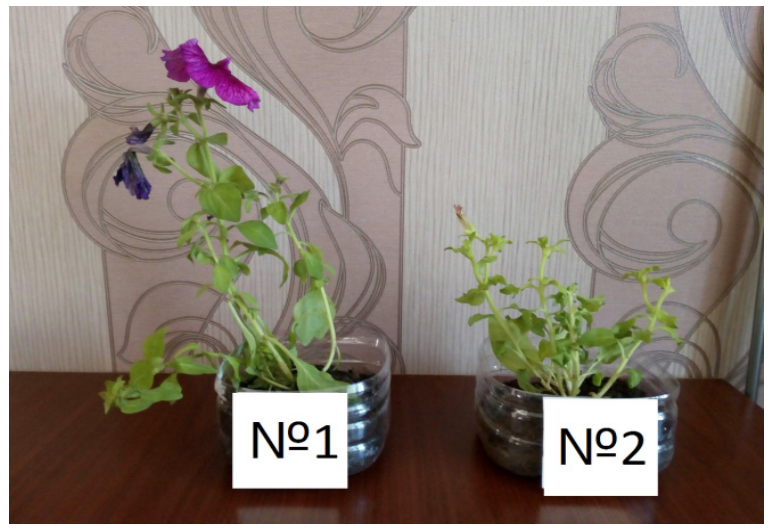

Fig. 5. Plants after 60 days.

Taking into account that in the laboratory experiment seedlings of petunia were grown in an artificial environment and did not reach their maximum biomass, when growing a flower crop under natural conditions, the values are expected to be higher. We can draw the conclusion about the prospects for further research of this plant in order to use it for phytoremediation of contaminated urbanized soils with copper and zinc pollution reaching the value of $5 \mathrm{MAC}$.

\section{CONCLUSIONS}

The proposed measure to minimize soil pollution in the city of Novokuybyshevsk should reduce the negative impact of anthropogenic sources on the environment. Moreover, the measure decreases the pollution of the atmosphere, soil and water, as well as reduces damage to the animal and plant world, which leads to a more beneficial state of the environment.

A separate and equally important area of research is the in-depth consideration of the issue of utilization of contaminated plant biomass in order to prevent recontamination of various ecosystem components with their subsequent entry into food chains.

As an example, for the concentration of heavy metals the following can be done:

1) burning plants with coal in the furnace of a thermal power station

2) composting (using plant biomass as intermediate layers of a landfill).

\section{REFERENCES.}

[1] O.I. Marari, "Quality of Life in Modern Metropolitan Area: Regional Aspect," in Region: Systems, Economics, Management, vol.4 (15), 2011, pp. 61-65.

[2] I.F. Sukhacheva, L.E. Orlova, O.N. Isakova, L.I. Bedareva, L.V. Pavlova, A.A. Sapukova, T.V. Sudakova, N.M. Toropova, "Health and Hygienic State of the Soil in Samara: Possible Risks to Public Health," in Proceedings of the Samara Scientific Center of the Russian Academy of Science, vol.1 (6), 2010, pp. 1516-1523.

[3] A.V. Zhogoleva, "Post-Industrial Urban Planning for Steady Development of Urban Areas, Tradition and Innovation" in Construction and Architecture: Urban Planning, Samara, 2015, pp. 54-60.

[4] N.A. Lekareva, "Spatial Resources of the City," in Volga Scientific Journal, vol.3 (31), 2014, pp. 107-110.

[5] E. M. Nikiforova, N. E.Kosheleva, "Dynamics of pollution of urban soils with lead (for example, the eastern district of Moscow)" in Soil science, vol.8, 2007, pp.984-997.

[6] O.V.Plyaskina, D.V.Ladonin "Heavy metal pollution of urban soils," in Eurasian Soil Science, vol.42, № 7, 2009, pp. 816-823.

[7] O.V. Plyaskina, D.V. Ladonin, "Heavy metal pollution of urban soils," in Eurasian Soil Science, vol.42, № 7, 2009, pp. 816-823.

[8] E. M. Kuramshin, N. G.Kuramshina, E. E. Nurtdinova, U. B. Imashev, "Geochemical assessment of heavy metal contamination of urban soils of Bashkortostan" in Bashkir chemical journal, vol. 2, 2015, pp. 74-79.

[9] A.I. Ilyasova, T W Malikova, "Study the possibility of assessing the environmental quality of the City of Ufa with phytoindication" in the II International scientific-practical conference: Ecological safety and protection of the natural environment, 2014, pp. 53-55.

[10] O. G. Beriev, "Soil contamination of urban areas with heavy metals as a factor affecting the health of citizens" in the V International extramural scientific-practical conference, 2015, pp. 168-175.

[11] A. A. Mironov, A. A. Mironov, E. A. Beaver, E. A. Bobrov, "Contamination of urban soils of the Smolensk region" in the Materials of International scientific-practical conference, 2015, pp. 16-18.

[12] T. N. Vasiliev, "Fitoremediation the territory of the Urban agglomeration" in Bulletin of the Orenburg scientific center Ural branch of RAS, 2014, № 2, pp. 12.

[13] T. N. Vasiliev, "Phytoremediation determination of $\mathrm{Pb}, \mathrm{Cd}, \mathrm{Zn}$ in the Orenburg district," in Bulletin of the Orenburg state University, vol.6, 2014, pp. 13-17.

[14] M. V. Dzampaeva, M. V. Zernov, S. A. Bekuzarova, "Rehabilitation of contaminated land," in Proceedings of the international extramural student conference, 2017, pp.303-306.

[15] S. A. Bekuzarova, Turieva V. M., D. A. Gazzaev, "Reducing toxicity of soil," in Works of young scientists of Vladikavkaz scientific centre of the RAS, vol. 4, № 4, 2013, pp. 51-55.

[16] N. P. Nevedrov, "Cultural use of plants to phytoremediation of soils Kursk region" in the Collection of reports and abstracts of the Moscow international summer schools, 2014, pp. 58-63.

[17] I. N. Shilin, "Phytoremediate as a promising method of revitalization mostpromising territories," in Innovations in landscape architecture materials of the VIII scientific-practical conference, 2012, pp. 81-83.

[18] A.I. Murzayeva, Y.M. Galitskova, "Urban soil contamination," in Procedia Engineering, vol. 153, 2016, pp.162-166. 